\title{
MITI yens for regional aid
}

\section{Nagoya, Hiroshima \& Kyushu}

JAPAN's Ministry of International Trade and Industry (MITI) is about to throw a few peanuts to its regional research institutes far from Tokyo in the hope of stimulating joint research between local industry and government.

Despite the boom in research and development in the private sector, Japan's government laboratories have suffered a financial squeeze for the past decade.

Built in the period of rapid industrial growth between the 1950 s and the 1970 s, MITI's regional laboratories in Hokkaido, Tohoku, Nagoya, Chugoku (a

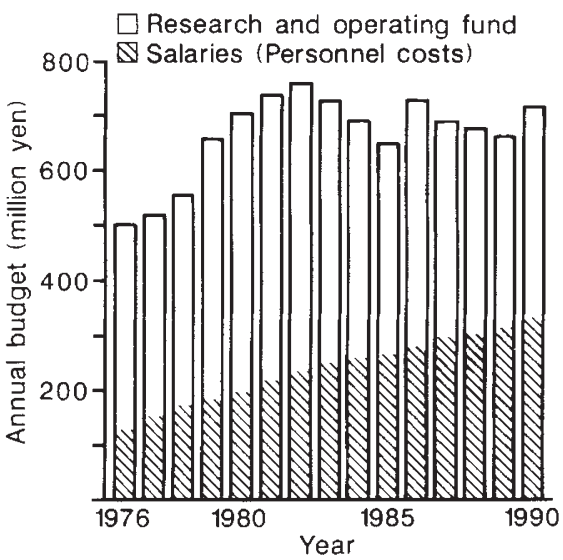

region around Hiroshima) and Kyushu at first enjoyed quite rapid growth, both in money and people. But in the early 1980 s, as the national budget suffered due to huge spending on public works - on roads and railways for bullet trains, for example - the Ministry of Finance clamped down on government spending. Government appointments (those of researchers included) were frozen, as were the general accounts for research and development of science-related ministries and agencies. In MITI's case, general account spending was forced down by a fixed percentage every year.

The result? Stagnation. The budget for MITI's Government Industrial Research Institute in Chugoku (GIRIC) shows what has happened (see figure). After growing at an average annual rate of more than 10 per cent until the early $1980 \mathrm{~s}$, the institute's total budget has since remained a level $¥ 700$ million ( $\$ 5.4$ million). Staff numbers have been almost constant at just over 50 . But, with salary inflation, salaries have been eating up an increasingly larger share of the budget - nearly 50 per cent in 1990 compared with just over 25 per cent in 1976.

MITI has tried to cope with the steady erosion of its general account by drawing on its special account budgets, which are derived from taxes on oil and electricity and which are not subject to Ministry of Finance ceilings. While MITI's general account for research and development has fallen from $¥ 85,000$ million ( $\$ 670$ million at current exchange rate) in 1980 to $¥ 68,492$ million ( $\$ 540$ million) this year, the special accounts have more than doubled, from $¥ 72,435$ million to $¥ 153,140$ million $(\$ 1,206$ million), in the same period.

MITI has also won extra funds of $¥ 26,000$ million a year by the establishment of the Japan Key Technology Centre, funded by dividends of governmentheld shares of the recently privatized domestic telecommunications company, Nippon Telegraph and Telephone. But little of this money has filtered through to MITI's regional laboratories, still mostly dependent on the general account.

MITI has also had some success, in these hard times, in herding Japanese companies together into research consortia that work in collaboration with MITI institutes but are fed with only minimal amounts of government money. These include MITI's optoelectronic research projects and the recently established superconductivity research consortium headed by Shoji Tanaka of Tokyo University. But only MITI's larger laboratories near Tokyo, such as the Electrotechnical Laboratory (ETL) in Tsukuba, have gained from these ventures.

This may be about to change. MITI's budget request for next fiscal year includes a tiny request for $¥ 15$ million $(\$ 115,000)$ under the category of "regional largescale projects". Hitherto, such funds have been used only by MITI's regional research institutes, but the new money is earmarked for private industry in the vicinity of MITI's regional institute at Nagoya, and is intended to stimulate the already well-developed government/industry research on advanced ceramics in that area (see Nature 348, 186; 1990).

Katsuhiko Umehara, senior deputy director of MITI's Agency of Industrial Science and Technology (AIST), says that MITI now aims to have at least one such project for each of its seven regional laboratories. The laboratories will act as regional coordinators of the research.

Although the amounts of money involved in this initiative are minuscule, about $\$ 1$ million a year at most, one of MITI's traditional skills is that of goading industry into action with limited government funds.

A prime mover behind the new initiative is Katsuya Nakayama, directorgeneral of GIRIC near Hirsohima. He has recently organized several symposia to introduce academics and industrialists in the Chugoku area to new MITI initiatives such as the Human Frontier Science Programme and the Intelligent Manufacturing System (IMS) project.

David Swinbanks

\section{Controlling the tides}

\section{Hiroshima}

DESPITE its shoestring budget, MITI's Government Industrial Research Institute, Chugoku (GIRIC), near Hiroshima, has succeeded in building one of the largest hydraulic models in the world with its 230 metre-long scale model of the Seto Inland Sea. Built at a cost of $¥ 1,600$ million ( $\$ 12$ million), the model comes complete with artificial tides, currents and 73 rivers which together replicate precisely conditions in

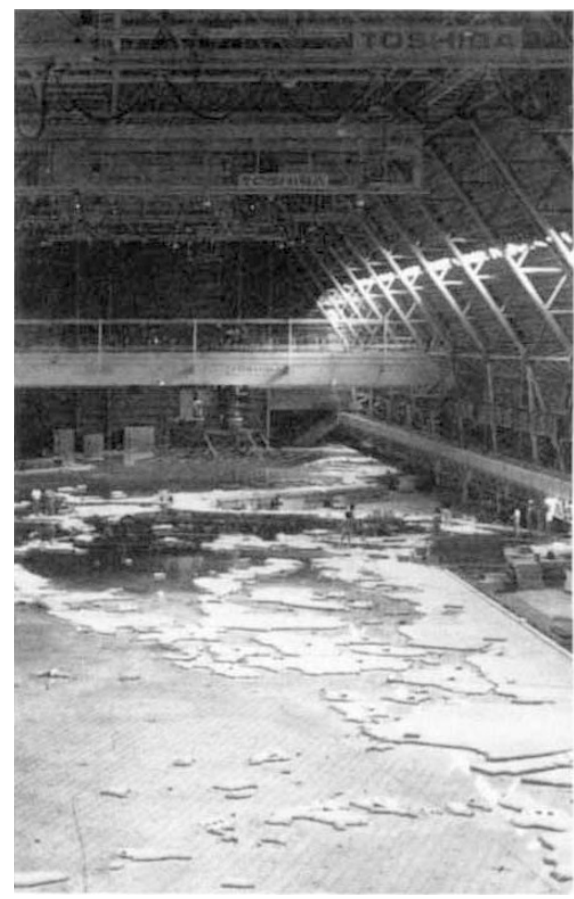

Monitoring the path of pollution.

the real sea which lies between the mainland Japan and the island of Shikoku.

One of the aims of the model is to come up with ways of artificially modifying water flow in order to reduce the severe pollution caused by industry, agriculture and waste from the large cities of Osaka and Hiroshima which border the sea. To provide effective answers from a scale model, fluctuations of the water surface have to be controlled to an accuracy of about a millimetre. A laser system is used that continuously feeds water-level readings back to a computer that commands a huge hydraulically operated system of weirs. A complete annual cycle of tides can be modelled in just 55 hours.

After completion in 1973, it took several years work by 25 researchers to fine-tune the model. Now that it is performing well, GIRIC researchers are experimenting by removing islands or creating new channels to find out the effects on flow. By introducing coloured water, they can monitor the path of pollutants. In one experiment, researchers at GIRIC have created a channel leading out of Osaka Bay, a site of stagnant flow and major pollution, to see if pollutants can be flushed out into the Pacific Ocean.

David Swinbanks 